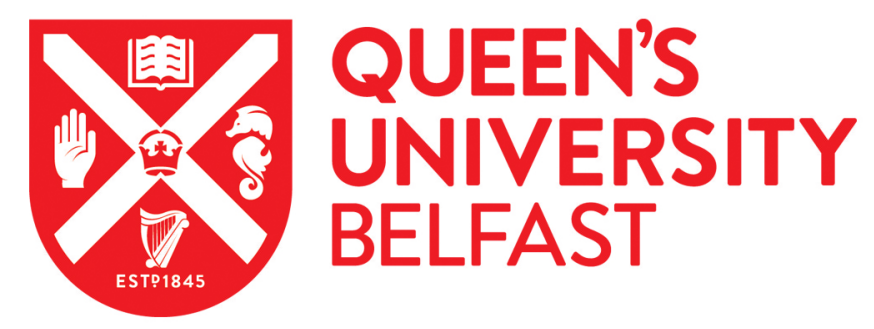

\title{
'Take more laxatives was their answer to everything': A qualitative exploration of the patient, carer and healthcare professional experience of constipation in specialist palliative care
}

Hasson, F., Muldrew, D., Carduff, E., Finucane, A., Graham-Wisener, L., Larkin, P., McCorry, N. K., Slater, P., \& Mcllfatrick, S. (2019). 'Take more laxatives was their answer to everything': A qualitative exploration of the patient, carer and healthcare professional experience of constipation in specialist palliative care. Palliative Medicine. https://doi.org/10.1177/0269216319891584

\section{Published in:}

Palliative Medicine

\section{Document Version:}

Publisher's PDF, also known as Version of record

Queen's University Belfast - Research Portal:

Link to publication record in Queen's University Belfast Research Portal

\author{
Publisher rights \\ (C) 2019 The Authors. \\ This is an open access Creative Commons Attribution-NonCommercial License (https://creativecommons.org/licenses/by-nc/4.0/), which \\ permits use, distribution and reproduction for non-commercial purposes, provided the author and source are cited.
}

\section{General rights}

Copyright for the publications made accessible via the Queen's University Belfast Research Portal is retained by the author(s) and / or other copyright owners and it is a condition of accessing these publications that users recognise and abide by the legal requirements associated with these rights.

Take down policy

The Research Portal is Queen's institutional repository that provides access to Queen's research output. Every effort has been made to ensure that content in the Research Portal does not infringe any person's rights, or applicable UK laws. If you discover content in the Research Portal that you believe breaches copyright or violates any law, please contact openaccess@qub.ac.uk. 


\title{
'Take more laxatives was their answer to everything': A qualitative exploration of the patient, carer and healthcare professional experience of constipation in specialist palliative care
}

Palliative Medicine

1-10

(C) The Author(s) 2019 (c) (i) (3)

Article reuse guidelines: sagepub.com/journals-permission DOI: $10.1177 / 0269216319891584$ journals.sagepub.com/home/pmj

@SAGE

\author{
Felicity Hasson ${ }^{1}(\mathbb{D})$, Deborah Muldrew ${ }^{1}(\mathbb{D})$ Emma Carduff ${ }^{2}$, \\ Anne Finucane $^{3}{ }^{(\mathbb{D})}$, Lisa Graham-Wisener ${ }^{4}$, Phil Larkin ${ }^{5}$, \\ Noleen Mccorry ${ }^{4}$, Paul Slater ${ }^{1}$ and Sonja Mcllfatrick ${ }^{1}$ (D)
}

\begin{abstract}
Background: Constipation is a major problem for many older adults, more so for those who are receiving specialist palliative care. However, limited research reports the subjective experiences of constipation, despite evidenced differences between the healthcare professional and patient/carer perspective.

Aim: The main aim of this study is to explore the experience of how constipation is assessed and managed within specialist palliative care from the patient, carer and healthcare professional perspective.

Design: Exploratory, qualitative design, utilising focus groups and interviews, and analysed using thematic analysis.

Setting/participants: Six focus groups with 27 healthcare professionals and semi-structured interviews with 13 patients and 5 family caregivers in specialist palliative care units across three regions of the United Kingdom.

Results: Constipation impacted physically, psychologically and socially on patients and families; however, they felt staff relegated it on the list of importance. Lifestyle modifications implemented at home were not incorporated into their specialist palliative care plan within the hospice. Comparatively, healthcare professionals saw constipation solely as a physical symptom. Assessment focused on the physical elements of constipation, and management was pharmacologically driven. Healthcare professionals reported patient embarrassment as a barrier to communicating about bowel care, whereas patients wanted staff to initiate communication and discuss constipation openly.

Conclusion: Assessment and management of constipation may not yet reflect the holistic palliative care model. A focus on the pharmacological management may result in lifestyle modifications being underutilised. Healthcare professionals also need to be open to initiate communication on bowel care and consider non-pharmacological approaches. It is important that patients and families are supported in self-care management, alongside standardised guidelines for practice and for healthcare professionals to facilitate this.
\end{abstract}

\section{Keywords}

Constipation, symptom management, palliative care, hospice, quality of care, qualitative research

${ }^{1}$ Ulster University, Newtownabbey, UK

${ }^{2}$ Marie Curie Hospice, Glasgow, Glasgow, UK

${ }^{3}$ Marie Curie Hospice, Edinburgh, Edinburgh, UK

${ }^{4}$ Queen's University Belfast, Belfast, UK

${ }^{5}$ University of Lausanne, Lausanne, Switzerland
Corresponding author:

Sonja Mcllfatrick, School of Nursing, Ulster University, Shore Road, Newtownabbey BT37 0QB, Co Antrim, UK.

Email: sj.mcilfatrick@ulster.ac.uk 


\section{What is already known about the topic?}

- Constipation is a major problem for many older adults, more so for those who are receiving specialist palliative care.

- The patient and caregiver perspective are largely unreported in the literature, despite differences between the healthcare professionals and patient's reports of the impact and severity of constipation.

\section{What this paper adds?}

- Constipation impacts on patients and families physically, psychologically and socially.

- Healthcare professionals' focus on the physical symptoms of constipation during assessment, leading to an overreliance on pharmacologically driven management.

- Non-pharmacological techniques used by patients and families at home were not incorporated into the plan of care in this setting, potentially impacting on overall self-care management.

\section{Implications for practice, theory or policy}

- A holistic approach to constipation care is required to meet the needs of patients and families.

- Healthcare professionals should routinely offer advice on non-pharmacological interventions alongside pharmacological interventions to patients as part of their plan of care.

- It is important that patients and families are supported by healthcare professionals to take control of self-management and to more effectively use their own strategies.

\section{Introduction}

Constipation is a major problem, and significant concern, for many older adults. It is determined by unsatisfactory defecation due to infrequent stools, difficulty passing stools or the sensation of incomplete emptying. ${ }^{1}$ Factors significantly related to the presence of constipation include a diagnosis of cancer, bed restriction and the need for personal assistance for toilet visits. ${ }^{2}$ National and European clinical guidelines for the management of constipation for patients receiving palliative care ${ }^{3,4}$ identify key clinical messages including an essential comprehensive assessment, ongoing preventive measures, pharmacological and non-pharmacological management strategies of equal importance and particular attention during opioid therapy or in suspected cases of intestinal obstruction.

While approximately one-third of older adults are affected by constipation, ${ }^{5}$ this increases to over two-thirds of people admitted to specialist palliative care. ${ }^{6,7}$ However, a longitudinal study found that admission to a specialist palliative care unit did not improve constipation symptoms, and prevalence significantly increased in the palliative care unit. ${ }^{8}$ Specialist palliative care is offered within hospices in the United Kingdom for patients throughout the trajectory of a terminal illness, focused on improving quality of life through pain and symptom management, supporting the individual and their loved ones and advising on practical concerns. ${ }^{9}$ Eighty percent of patients accessing specialist palliative care inpatient services in the United Kingdom have a diagnosis of cancer and typically are admitted as a planned series of short stays. ${ }^{10}$

Evidence regarding the impact of constipation on patients is inconsistent and lacking within specialist palliative care. While a systematic review of four papers on older people's experiences suggests physical, psychological and social impact, ${ }^{11}$ data from an Australian Palliative Care database suggests that most palliative care patients were not unduly distressed by constipation. ${ }^{12}$ Furthermore, underestimation of symptom intensity by healthcare professionals leads to increased risk of inadequate treatment, ${ }^{13}$ and research in chronic pain has demonstrated incongruence between the patient experience and the healthcare professional's assessment in the perceived importance and severity of constipation. ${ }^{14}$ Limited research studies explore the patient/carer perspective of this distressing symptom and concomitant comparison to the healthcare professional perspective. To provide a holistic insight into the assessment and management of constipation, this article explores the experiences of the patient/carer and healthcare professional of constipation in specialist palliative care.

\section{Methods}

\section{Design}

An exploratory qualitative design was used with reporting guided by the Standards for Reporting Qualitative Research framework. ${ }^{15}$ Focus groups were conducted with healthcare professionals to understand the experiences of assessing and managing constipation and individual or dyad interviews with patients and carers to capture individual experiences.

\section{Setting}

Focus groups with healthcare professionals were conducted in three specialist palliative care inpatient units across Northern Ireland, England and Scotland, with, on 
Table 1. Inclusion/exclusion criteria.

\begin{tabular}{|c|c|c|}
\hline \multirow[t]{2}{*}{$\mathrm{HCPs}$} & Inclusion criteria & $\begin{array}{l}\text { 1. Employed by Marie Curie as an HCP } \\
\text { 2. Had previous experience working with patients receiving palliative care who suffer from } \\
\text { constipation } \\
\text { 3. Willing to participate in the study and have provided informed consent } \\
\text { 4. Aged } \geqslant 18 \text { years }\end{array}$ \\
\hline & Exclusion criteria & $\begin{array}{l}\text { 1. Agency staff } \\
\text { 2. Unregistered HCPs } \\
\text { 3. No experience of working with palliative care patients who have suffered from constipation }\end{array}$ \\
\hline \multirow[t]{2}{*}{ Patients } & Inclusion criteria & $\begin{array}{l}\text { 1. Experienced symptoms of constipation as assessed by the clinical team } \\
\text { 2. Emotionally and physically able to participate as assessed by the clinical team } \\
\text { 3. Aged more than } 18 \text { years } \\
\text { 4. Able to provide written consent and communicate in English }\end{array}$ \\
\hline & Exclusion criteria & $\begin{array}{l}\text { 1. Have not experienced constipation } \\
\text { 2. Diagnosed with inflammatory bowel disease or ant GI disease of organic cause with } \\
\text { associated constipation } \\
\text { 3. Deemed physically or emotionally unable to participate }\end{array}$ \\
\hline \multirow[t]{2}{*}{ Caregivers } & Inclusion criteria & $\begin{array}{l}\text { 1. The person they care for agreed they could be approached } \\
\text { 2. Emotionally and physically able to participate } \\
\text { 3. Aged more than } 18 \text { years } \\
\text { 4. Able to provide written consent and communicate in English }\end{array}$ \\
\hline & Exclusion criteria & $\begin{array}{l}\text { 1. Carers who are paid } \\
\text { 2. Aged less than } 18 \text { years } \\
\text { 3. Have not obtained the patient's approval to be approached }\end{array}$ \\
\hline
\end{tabular}

HCP: healthcare professional.

average, 22 beds and admitting approximately 329 patients each year. Patient/carer interviews were conducted in one specialist palliative care inpatient unit in the United Kingdom.

\section{Sampling}

A purposive sample of healthcare professionals was invited to participate if they met the inclusion criteria (Table 1). Data were collected until theoretical sufficiency was achieved, which was identified as the point at which a sufficient range, complexity, subtlety, resonance and external validity had been reached to allow the research team to address the aim of the research. ${ }^{16,17}$ The research lead identified potential participants and provided study details and a consent form. If interested, healthcare professionals were asked to return their completed consent form to the researcher.

Healthcare professionals within the hospice who were external to the research team acted as gatekeepers to screen patients. A purposive sample of patients experiencing constipation and admitted to a specialist palliative care unit in the United Kingdom, and their informal caregivers, were invited to participate (Table 1). Data were collected until theoretical sufficiency was achieved. ${ }^{16,17}$ Eligible patients were approached by a nurse with study details and a consent to be contacted form. If they consented, they received a phone call from the Researcher (D.M.), and the study was explained. Patients were also asked if their main carer could be approached. If consent was obtained, they were contacted to undertake a joint or independent interview.

\section{Data collection/processing}

Focus groups were held from November 2016 to January 2017. Each focus group included between three and six participants to allow for discussion on variation of experience relative to the topic. ${ }^{18}$ Focus groups were held by the researcher (D.M.) within the specialist palliative care units during work hours and, with permission, digitally recorded. A note-taker was present to capture information and observations arising from the discussion. A demographic questionnaire was completed before the focus group. The focus group schedule (Appendix 1) focused on experiences of constipation assessment and management from the perspectives of healthcare professionals. Each focus group proposed to last 45-60 min.

Interviews with patients/carers were undertaken by the researcher (D.M.) from February to July 2017. Interviews were arranged at a time convenient to the participant. An interview schedule (Appendix 1) was developed from the core elements of the UK National Clinical Guidelines on constipation ${ }^{3}$ to capture the participant's understanding and experiences of constipation assessment and management. Interviews were expected to last 15-30 min, including a demographic questionnaire and were audio recorded with the participant's permission.

All audio files were password protected and sent for transcription outside the research team. Once transcribed, 
a $10 \%$ randomly selected sample was checked for transcription errors.

\section{Data analysis}

An emic viewpoint was collected from patients/caregivers with lived experience of a phenomenon, whereas an etic perspective was collected from people who are experts and stakeholders in the area but not directly living with the phenomena, that is, healthcare professionals. ${ }^{19}$ Therefore, analysis of data was undertaken sensitively with consideration of how constipation was interpreted by the participant who was experiencing the symptom compared to the participant who was treating the symptom. A thematic analysis was undertaken by D.M., S.M. and F.H., guided by Braun and Clark's framework. ${ }^{20}$ Patient/Carer and healthcare professional data were analysed independently, and selected quotes were indicative of a range of views presented by participants. Triangulation occurred through the integration of focus group and interview data during the interpretation stage. ${ }^{21}$

\section{Rigour}

In line with Lincoln and Guba's ${ }^{22}$ recommendations, steps were taken to increase trustworthiness of the findings. A reflexive journal was maintained. The researcher was from a non-nursing background and had no prior connections with the specialist palliative care unit or staff. Relationships were established through multiple points of communication. A thick description supported transferability, an audit trail determined dependability, and credibility was established by feeding back to participants, and analysing contradictory/negative cases.

\section{Ethics}

Full University Research Ethical Approval was obtained (Application 16/WM/0352), and hospice research governance approval was obtained at each site. The study was explained to participants in writing and verbally and informed consent collected. Participants were informed about their right to withdraw, confidentiality and the disclosure of sensitive information. Lone worker and distress protocols were in place, and a support pack was provided to all participants. Anonymity ensured no participant could be identified.

\section{Results}

\section{Patient/carer profile}

The gatekeeper identified 66 patients who met the eligibility criteria. Reasons for exclusion included severity of illness $(n=34)$, unwillingness to participate $(n=11)$ or patients were being discharged $(n=5)$. Of the 16 patients
Table 2. Demographic profile of patients and carers.

\begin{tabular}{llll}
\hline & & Patient, n (\%) & Carer, n (\%) \\
\hline Gender & Male & $4(30.8)$ & $1(20.0)$ \\
Age & Female & $9(69.2)$ & $4(80.0)$ \\
& $25-34$ & - & $1(20.0)$ \\
& $35-44$ & - & - \\
& $45-54$ & $1(7.7)$ & $1(20.0)$ \\
Previous & $55-64$ & $3(23.1)$ & $2(40.0)$ \\
constipation of & Always & $1(7.7)$ & $1(20.0)$ \\
the patient & Often & $1(7.7)$ & - \\
& Sometimes & $3(23.1)$ & $2(40.0)$ \\
Extent of & Never & $8(61.5)$ & $3(60.0)$ \\
concern & A lot & $9(69.2)$ & $2(40.0)$ \\
& A little & $3(23.1)$ & $3(60.0)$ \\
Satisfaction with & Not at all & - & - \\
constipation & Neutral & $1(7.7)$ & $1(20.0)$ \\
management & Satisfied & $4(30.8)$ & - \\
& Very satisfied & $7(53.8)$ & $3(60.0)$ \\
& Missing & $1(7.7)$ & $1(20.0)$ \\
\hline
\end{tabular}

who consented, three died prior to interview. Thirteen patients and five carers agreed to be interviewed (Table 2). Nine patients (69.2\%) were receiving opioids, and 11 (84.6\%) were prescribed laxatives. Carers had been providing care between 1 and 5 years to a parent $(n=2,40 \%)$ or spouse $(n=3,60 \%)$.

\section{Healthcare professional profile}

Twenty-seven healthcare professionals participated across six focus groups. All participants were female, and more than half were employed as nurses. The most common qualification was a Bachelor's degree, and approximately, half had received post-qualification training in constipation. The mean length of employment within the specialist palliative care unit was 5 years, and the mean length of experience within specialist palliative care settings was 8 years (Table 3 ).

\section{Main findings}

Three themes were drawn out from the data: (1) constipation under-recognised as a multifaceted symptom, (2) the physical focus on constipation assessment with less emphasis on psychosocial aspects and (3) pharmacological management of constipation dominates in specialist palliative care.

Theme 1: constipation under-recognised as a multifaceted symptom. Patients reported a complex, multifaceted symptom with physical, psychological and social implications. Physically, constipation caused pain, bloating, cramps, appetite suppression, bleeding and tearing. 
Table 3. Demographic profile of HCPs.

\begin{tabular}{|c|c|}
\hline Characteristics & $\mathrm{N}(\%)$ \\
\hline \multicolumn{2}{|l|}{ Location } \\
\hline Northern Ireland & $8(29.6)$ \\
\hline Scotland & $8(29.6)$ \\
\hline England & $11(40.7)$ \\
\hline \multicolumn{2}{|l|}{ Gender } \\
\hline Male & $0(0)$ \\
\hline Female & $27(100)$ \\
\hline \multicolumn{2}{|l|}{ Age } \\
\hline $18-24$ & $2(7.4)$ \\
\hline $25-34$ & 7 (25.9) \\
\hline $35-44$ & $5(18.5)$ \\
\hline $45-54$ & 7 (25.9) \\
\hline $55-65$ & $6(22.2)$ \\
\hline \multicolumn{2}{|l|}{ Job role } \\
\hline Nurse & 14 (51.9) \\
\hline Doctor & 7 (25.9) \\
\hline HCA & $4(14.8)$ \\
\hline Pharmacist & $1(3.7)$ \\
\hline Physiotherapist & $1(3.7)$ \\
\hline \multicolumn{2}{|l|}{ Employment type } \\
\hline Full time & 14 (51.9) \\
\hline Part time & $11(40.7)$ \\
\hline Missing & $2(7.4)$ \\
\hline \multicolumn{2}{|l|}{ Education } \\
\hline Associate diploma & $2(7.4)$ \\
\hline Bachelors of Science & $10(37.0)$ \\
\hline Graduate certificate & $1(3.7)$ \\
\hline Graduate diploma & $3(11.1)$ \\
\hline Masters of Science & 7 (25.9) \\
\hline Other & $3(11.1)$ \\
\hline Missing & $1(3.7)$ \\
\hline \multicolumn{2}{|l|}{ Training (assessment) } \\
\hline Yes & 14 (51.9) \\
\hline No & $13(48.1)$ \\
\hline \multicolumn{2}{|l|}{ Training (management) } \\
\hline Yes & $15(55.6)$ \\
\hline No & $12(44.4)$ \\
\hline \multicolumn{2}{|l|}{ Training (treatment) } \\
\hline Yes & $15(55.6)$ \\
\hline No & $12(44.4)$ \\
\hline
\end{tabular}

HCP: healthcare professional; HCA: healthcare assistant.

Psychologically, patients reported being short tempered, feeling dread when going to the toilet, anxiety that exacerbated other conditions and embarrassment running to the toilet constantly but with no bowel movement. Socially, patients felt trapped, not wanting to leave the nearby bathroom and the lethargy resulting from constipation reduced their desire to socialise:

They need to realise the impact it has on the patient and how distressing it can be. Most people think constipation will just pass, I'll be okay. But when you're living with it, it can be distressing. Patient_8, pg7
You are completely housebound until the dam breaks. You are scared of going somewhere and something happening. Patient_3,pg3

Prior to admission to specialist palliative care, carers played a key role in the monitoring and management of constipation using pharmacological (using laxatives and/or enemas), lifestyle and diet changes (such as increased fibre and fluids). They were acutely aware of the impact on the patients psychologically and on their social well-being, negatively affecting their quality of life, which also had repercussions on the caregiver's life. For example, anxiety was experienced during hospital trips to help the patient with the pain caused by constipation. However, despite the holistic impact of constipation, patients/carers perceived it to be relegated on the list of importance by healthcare professionals, and the onus of responsibility was on them to remind staff of their concerns:

It has stressed him out, which means his anxiety levels have been raised and [his] breathing is affected, which has a knock-on effect on the family, because that's where we come into play. As a result, it has been stressful for us. Carer_4, pg1

But [suppositories] was our management of it. I suggested it. I had read up on it and I suggested. We managed it ourselves. Carer_2, pg5

Healthcare professionals approached constipation in terms of the physical bowel movements, reporting a straightforward, perceived easy-to-manage symptom in relation to what they perceive as more complex symptoms that is expected within specialist palliative care due to the high prescription of analgesics, notably opioids. They reported the physical manifestation of the symptom of primary importance and approached assessment and management from an objective measurement of bowel movement rather than a subjective assessment of a patient's expectations of bowel frequency, stool volume and consistency. One nurse identified anxiety as a potential effect; however, no healthcare professionals reported the social impact:

Constipation is often seen as a simple thing . . . It's pretty straight forward. Nurse, FG1, pg23

Patients are on opioids and we do have a lot of patients come in, particularly in the community, who are not on laxatives. Nurse, FG2, pg9

Patients/carers believed healthcare professionals lacked an understanding and awareness of the severity and holistic impact of constipation on their lives, which they believed resulted in it being given less priority than other symptoms. They also felt responsible for reminding the healthcare professional of the importance of the 
symptom by initiating the conversation and the need for follow-up in its management. However, constipation remains difficult to talk about for both the patient, carer and for some healthcare professionals with most consultations typically focused on the characteristics of the disease. Healthcare professionals recognised that the assessment of constipation was tool driven, with management predominately focused on pharmacological responses. When discussing training on constipation, healthcare professionals perceived it to be either missing or as a small component within a larger curriculum:

I don't think staff take much account when [a bowel movement] does happen. They're not asking me very often if I had a bowel movement, or how was it? P8, pg4

I feel like I have had, not actual training, nothing online like e-learning or like that but a lot of us have learned somewhere. Nurse, FG4, pg7

Theme 2: physical focus on constipation assessment with less emphasis on psychosocial aspects. Assessment involved an objective review of physical symptoms, comprising a physical examination, recording a bowel history, identification of physical symptoms and completion of an assessment tool, such as the Bristol Stool Chart. Physical assessment dominated the conversation, with only a few participants noting preventive strategies, such as medication review and dietary considerations. Healthcare professionals indicated a potential challenge in ensuring compliance with taking laxatives reporting that sometimes, patients preferred to suffer from constipation 'so they're not incontinent' (FG1, pg14). Despite recognition that outside the specialist palliative care setting, the family and patient largely self-managed the condition privately, upon entry to the inpatient setting responsibility for managing the condition was transferred to the multidisciplinary team, with the nurse often taking a lead role:

It's theoretically a multi-disciplinary approach, including the patient and family. But I think it tends to fall to the nurses and the doctors. Nurse, FG4, pg6

While healthcare professionals reported a comprehensive assessment, patients/carers felt it was something staff did not take much account of, with one carer recalling that it was not mentioned until the patient raised it as a concern. Patients noted that the healthcare professionals were reluctant to bring up the topic, attributing this to be an embarrassing and personal symptom, noted by only briefly inquiring into current laxative use or not mentioning constipation until it was actively raised by the patient:

Well they didn't say, 'Do you need one?' As in a suppository. No, it would be more just basically, 'Have you been?' and I would say 'Yes' and that would be it'. Patient_3, pg8
I don't think it was ever mentioned until you [the patient] mentioned it. Carer_2, pg8

The challenge of initiating communication with patients was one of the main contributory factors perceived by patients as the under-appreciation of the severity of the symptom. However, patients felt that staff should help normalise the conversation and reduce anxiety by explaining that it is very common and what symptoms to anticipate:

When families are there . . . they are very embarrassed and want you to walk out of the room. Nurse, FG1, pg12

I would sometimes volunteer the information and then they would record it. But you think, if they're not asking me, maybe they're not thinking that it's of any great importance. Patient_8, pg5

Theme 3: pharmacological management of constipation dominates in specialist palliative care. It was found that management was predominantly pharmacologically driven, with many healthcare professionals referring to a preferred laxative, despite awareness that there is no evidence for one laxative over another. ${ }^{23}$ Tailoring treatment was discussed pharmacologically: however, many healthcare professionals also reported consideration of the patient's preference, including what was palatable:

Treatment choices, how you would individualise that depending on your patient. Whether the oral or rectal route is available, or can they only manage small volumes of liquid. Pharmacist, FG3, pg16

While healthcare professionals were aware of lifestyle modifications being a factor in the treatment of constipation, they believed that they were constrained in their implementation due to the reality of the patient's clinical condition. Healthcare professionals acknowledged that perhaps they were not incorporating the patient experience and perspective as much as they could do when managing this symptom:

You can't always implement the lifestyle modifications. You can't get people as mobile and you can't get them to take the volumes of fluid or make changes to their diet, less so than someone who is well. Pharmacist, FG3, pg4

We are very good at pharmacological interventions but more focus on what the patient can do for themselves and other non-pharmacological interventions would be useful. Nurse, FG4, pg14

At home, patients/carers managed constipation using both pharmacological and non-pharmacological approaches. Patients/carers discussed lifestyle modifications positively, aware of the importance of diet and 
Table 4. Key differences between healthcare professional and patient/carer experience.

\begin{tabular}{ll}
\hline HCPs & Patient/carer \\
\hline $\begin{array}{l}\text { Upon admission to the specialised unit, the healthcare professional } \\
\text { took over the responsibility of the management of constipation }\end{array}$ & $\begin{array}{l}\text { Prior to admission, the patient and carer managed the } \\
\text { condition and symptoms of constipation in the home } \\
\text { Consultations typically focused on the characteristics of the }\end{array}$ \\
$\begin{array}{l}\text { Detrimental impact of constipation on the quality of life } \\
\text { of the patient and carer not recognised } \\
\text { Comprehensive assessment of constipation perceived to be }\end{array}$ & $\begin{array}{l}\text { The subjective experience of the patient is not } \\
\text { recognised }\end{array}$ \\
$\begin{array}{l}\text { undertaken } \\
\text { Management of condition is influenced by the clinical condition }\end{array}$ & $\begin{array}{l}\text { Patient and carer lack of understanding of the } \\
\text { pharmacological approach and perceive a loss of control }\end{array}$ \\
\hline
\end{tabular}

exercising within their limits. While some reported the specialist palliative care unit did consider aspects such as diet and mobility, many believed more needed to be done to support changes in these lifestyle factors. Moreover, a lack of explanation about the pharmacological approach left patients/carers with questions and doubts on the effectiveness of the treatment process:

What they told me to do with the laxatives, didn't work. I mean, I told them it didn't work . . . I did mention it all the time . . . they just said take more laxatives and that was their answer to everything. Patient_9, pg4

He is used to managing it at home and he's perfectly capable of managing it, so I suppose he just thought l'Il just keep doing it myself. They certainly never mentioned it. Carer_2, pg8

I would eat more fruit at home if I was constipated at all; all I had to do was eat an orange. Patient_5, pg3

Patients were unaware of which laxatives they were taking and sometimes felt excluded, resulting in patients reporting a loss of sense of control and independence in the management of a private symptom:

You lose your responsibility for yourself while you're here. P1, pg7

I don't know what the names are, because there's nothing on the tablet. P5, pg4-5

An overall summary of the key differences between the healthcare professionals and patient/carers is outlined in Table 4.

\section{Discussion}

\section{Main findings}

This study explored the healthcare professional and patient/carer experience of the assessment and management of constipation in inpatient specialist palliative care settings. This research highlighted a difference from two perspectives on the perceived impact of constipation for patients, which is consistent with international research ${ }^{24}$ (Table 4). However, this study also adds the perspective of the caregiver who experienced both a psychological and social impact because of the patient's symptom and played a key role in its management at home. While healthcare professionals, patients and carers recognised that constipation is a difficult and uncomfortable topic to discuss, it was recognised as an important symptom to assess and manage.

Healthcare professionals focused on physical symptoms, while patients/families reported the physical, psychological and social impact. Healthcare professionals reported a comprehensive assessment compared to patients who felt this symptom was given lower priority. Management was pharmacologically driven, and nonpharmacological techniques used by patients and carers at home were not clearly incorporated in the specialist palliative care plan, leading patients/carers to lose selfcontrol in the management process. It was not that healthcare professionals were averse to non-pharmacological treatment but that the focus of assessment was on physical clinical elements, and questions existed around the appropriateness of some non-pharmacological approaches for palliative care patients/environments. Healthcare professionals perceived patient embarrassment as a barrier to communicating about bowel care, whereas patients wanted staff to initiate communication and discuss constipation openly.

Previous research reported limited patient distress relating to this symptom; ${ }^{12}$ however, the findings of this study suggest that constipation has a wider, holistic impact across multiple facets of daily living resulting in social, psychological and physical concerns. Clinical assessment is the cornerstone of individualised patient care and, in palliative care, assessment should be underpinned by the palliative approach which considers physical, psychological, social and spiritual concerns. ${ }^{25}$ However, this study found that while assessment from healthcare professional's perspective was comprehensive, the objectively driven focus on the physical elements of the condition resulted in patients/carers feeling their social and psychological needs were not understood, and the symptom was not prioritised until the patient raised it as 
a concern. Comprehensive assessment in palliative care is not only about focusing on the whole person, taking a biopsychosocial perspective, but also ascertaining the individuals own understanding of their illness and personal situation. It could be argued that perhaps healthcare professionals do not appreciate the relevance of this approach for this particular symptom. This highlights the need to draw attention to the wider impact of constipation for both the patient/carer and for healthcare professionals to tailor their approach to incorporate these aspects. One suggestion for tailoring assessment to incorporate the patient experience and voice, which would identify the holistic impact for the patient, comes from the growing literature around the use of patient-reported outcome measures (PROMS). Within palliative care, the incorporation of PROMS into routine clinical practice indicates improved patient outcomes at both an individual and systems level. ${ }^{26,27}$ This general approach is supported by a systematic review on constipation in specialist palliative care which reported the importance of an assessment that includes the patient's subjective experience of constipation alongside objective measures obtained through a physical examination. ${ }^{28}$

Healthcare professionals demonstrated good knowledge and emphasis on pharmacological management; however, the importance and application of other lifestyle modifications received less attention in this setting. This is despite the clinical guidelines on constipation management in palliative care, ${ }^{3}$ highlighting the importance of non-pharmacological strategies, including optimising toileting, privacy, diet and fluids and mobility. It is important to apply a whole person philosophy of care for patients/ families, as international research indicates that patients/ carers place importance in a holistic, person-centred approach to symptom management in palliative care, ${ }^{29}$ and clinical guidelines indicate that patients want to be involved in decisions about treatment and care. ${ }^{30}$ Contemporary healthcare policy, alongside academic literature within palliative care consistently emphasise the need to ensure patient/family engagement. ${ }^{31-33}$ Many concepts exist, such as co-production, self-care management and shared decision-making, which can be supported through education of patients/carers. ${ }^{34}$ According to Johnston et al., 35 'self-management in palliative care is about supporting the patient to be given the means to master or deal with their illness or the effects of their illness themselves' (p. 8). There is a dearth of evidence to understand the contribution of self-management support not only related to the assessment and management of constipation but more widely within palliative care. It is important that not only are patients/families prepared and supported to have a voice for self-management and to more effectively use their own strategies but also that healthcare professionals are able to facilitate this.

Similarity can be drawn from the discussion around the total pain concept ${ }^{36-38}$ and findings which demonstrated that pain assessment was suboptimal in that the subjective experience and other psychological, spiritual and social aspects were not noted. A key lesson which can be applied to constipation is the importance of assessment and management through a multidimensional lens that allows for the appreciation of all possible causes and influences.

\section{Strengths/weaknesses}

A key strength is the rigour used to capture and triangulate the emic and etic experiences of constipation, capturing the care recipient and provider perspective. However, caution is also required with interpretation, as there are two distinctive reports; one of the participants reporting the personal experience of constipation, and one of participants providing care as part of their professional role. Data from different healthcare professionals were analysed together; however, the goals of care for nurses and medics may vary. It must also be acknowledged that patients/carers were only selected from three inpatient units across the United Kingdom, and those who participated may be more comfortable talking about constipation or may be at a different stage of illness than those who were excluded by the gatekeeper; therefore, not reflective of patients deemed too unwell to participate.

\section{What this study adds}

Assessment and management of constipation in the United Kingdom may not yet reflect the holistic palliative care model for patients and families. Healthcare professionals need to consider non-pharmacological approaches and enable/facilitate the continuation of self-care management strategies and key learning and views of patients and caregivers. Healthcare professionals need to be open to initiating communication on bowel care and shifting the mindset from physical to a holistic understanding of the impact of living with the condition.

\section{Acknowledgements}

The authors would like to thank Professors Mike Clarke, Jo Coast, Max Watson, Dr John MacArtney, Ms Rachel Perry and Mrs Eileen Wright for their contribution to the wider research project from which this manuscript was developed.

\section{Author's Contribution}

All authors contributed to the conception and design of this work, acquisition, analysis and interpretation of data or drafting and revising it critically for intellectual content. All authors have approved the version to be published.

\section{Data sharing}

Further data can be accessed by contacting the corresponding author. 


\section{Declaration of conflicting interests}

The author(s) declared no potential conflicts of interest with respect to the research, authorship and/or publication of this article.

\section{Ethical approval}

Full ethical approval was obtained from the Office for Research Ethics Committees Northern Ireland (ORECNI) (application no. 16/WM/0352). Governance was provided by each specialist palliative care unit.

\section{Funding}

The author(s) disclosed receipt of the following financial support for the research, authorship and/or publication of this article: This research was funded by a research grant awarded to Prof. Sonja Mcllfatrick by Marie Curie UK (grant no. MCCC-RP-16-A20993).

\section{ORCID iDs}

Felicity Hasson (iD https://orcid.org/0000-0002-8200-9732

Deborah Muldrew (iD https://orcid.org/0000-0003-2845-1922

Anne Finucane (iD https://orcid.org/0000-0002-3056-059X

Noleen Mccorry iD https://orcid.org/0000-0002-8542-7665

Sonja Mcllfatrick (iD https://orcid.org/0000-0002-1010-4300

\section{References}

1. NICE. Constipation: clinical knowledge summaries, 2017, https://cks.nice.org.uk/constipation\#!topicsummary (accessed 13 December 2018).

2. Erichsen E, Milberg A, Jaarsma $T$, et al. Constipation in specialized palliative care: factors related to constipation when applying different definitions. Supp Care Cancer 2016; 24(2): 691-698.

3. National Clinical Effectiveness Committee. Management of Constipation in Adult Patients Receiving Palliative Care (National Clinical Guideline No. 10), November 2015, https:// www.gov.ie/en/collection/b34c3e-management-of-constipation-in-adult-patients-receiving-palliative-ca/?referrer=/ wp-content/uploads/2015/11/mgmt-of-constipationguideline.pdf/

4. Larkin PJ, Cherny NI, La Carpia D, et al. Diagnosis, assessment and management of constipation in advanced cancer: ESMO clinical practice guidelines. Ann Oncol 2018; 29(Suppl. 4): iv111-iv125.

5. Rey E, Rogers J, Petersen K-U, et al. Constipation in older people: a consensus statement. Int J Clin Pract 2016; 71(1): e12920.

6. Dzierzanowski T and Cialkowska-Rysz A. The occurrence and risk factors of constipation in inpatient palliative care unit patients vs. nursing home residents. Prz Gastroenterol 2018; 13(4): 299-304.

7. Mercadante S, Masedu F, Maltoni M, et al. The prevalence of constipation at admission and after 1 week of palliative care: a multi-center study. Curr Med Res Opin 2018; 34(7): 1187-1192.

8. Tsai J-S, Wu C-H, Chiu T-Y, et al. Symptom patterns of advanced cancer patients in a palliative care unit. Palliat Med 2006; 20(6): 617-622.
9. WHO. WHO definition of palliative care. World Health Organization, 2017, http://www.who.int/cancer/palliative/definition/en/ (accessed 12 April 2017).

10. National Council for Palliative Care. National survey of patient activity data for specialist palliative care services. London: National Council for Palliative Care, 2016.

11. Tvistholm N, Munch L and Danielsen AK. Constipation is casting a shadow over everyday life ? A systematic review on older people's experience of living with constipation. $J$ Clin Nurs 2017; 26(7-8): 902-914.

12. Clark K. A population study to explore the prevelence and severity of bowel problems in palliative care. Palliat Med 2018; 32(Suppl. 1): 3-30.

13. Laugsand EA, Jakobsen $G$, Kaasa $S$, et al. Inadequate symptom control in advanced cancer patients across Europe. Supp Care Cancer 2011; 19(12): 2005-2014.

14. LoCasale RJ, Datto C, Wilson H, et al. The burden of opioidinduced constipation: discordance between patient and health care provider reports. J Manag Care Spec Pharm 2016; 22(3): 236-245.

15. O'Brien BC, Harris IB, Beckman TJ, et al. Standards for reporting qualitative research. Acad Med 2014; 89(9): 1245-1251.

16. Nelson J. Using conceptual depth criteria: addressing the challenge of reaching saturation in qualitative research. Qual Res 2017; 17(5): 554-570.

17. Dey I. Grounding grounded theory: guidelines for qualitative inquiry. Cambridge, MA: Academic Press, 1999.

18. Barbour R. Doing focus groups (ed. U Flick). London: SAGE, 2007.

19. Gaber J. Seeing the community's perspective through multiple emic and etic vistas. Health Promot Int 2016; 32(6): daw043.

20. Braun V and Clarke V. Using thematic analysis in psychology. Qual Res Psychol 2006; 3(2): 77-101.

21. Lambert SD and Loiselle CG. Combining individual interviews and focus groups to enhance data richness. $J \mathrm{Adv}$ Nurs 2008; 62(2): 228-237.

22. Lincoln $Y$ and Guba E. Naturalistic inquiry. Newbury Park, CA: SAGE, 1985.

23. Candy B, Jones L, Larkin PJ, et al. Laxatives for the management of constipation in people receiving palliative care. Cochrane Database Syst Rev 2015; 5: CD003448.

24. Friedrichsen $M$ and Erichsen $E$. The lived experience of constipation in cancer patients in palliative hospital-based home care. Int J Palliat Nurs 2004; 10(7): 321-325.

25. World Health Organization. Palliative care, 2018, http:// www.who.int/news-room/fact-sheets/detail/palliativecare (accessed 29 November 2018).

26. Currow DC, Allingham $S$, Yates $P$, et al. Improving national hospice/palliative care service symptom outcomes systematically through point-of-care data collection, structured feedback and benchmarking. Supp Care Cancer 2015; 23(2): 307-315.

27. Antunes B, Harding R and Higginson IJ. Implementing patient-reported outcome measures in palliative care clinical practice: a systematic review of facilitators and barriers. Palliat Med 2014; 28(2): 158-175.

28. Muldrew DH, Hasson F, Carduff E, et al. Assessment and management of constipation for patients receiving palliative 
care in specialist palliative care settings: a systematic review of the literature. Palliat Med 2018; 32(5): 930-938.

29. Van der Eerden M, Hughes S, Varey S, et al. Person-centred palliative care in five European countries: the experiences of patients and family carers. Int J Integr Care 2016; 16(6): A162.

30. Richardson A. Improving supportive and palliative care for adults with cancer, Nursing Times, https://www.nice. org.uk/guidance/csg4/resources/improving-supportiveand-palliative-care-for-adults-with-cancer-pdf-773375005 (accessed 30 May 2018).

31. Belanger E, Rodriguez C, Groleau D, et al. Patient participation in palliative care decisions: an ethnographic discourse analysis. Int J Qual Stud Health Well-being 2016; 11: 32438.

32. Sudore RL, Casarett D, Smith D, et al. Family involvement at the end-of-life and receipt of quality care. J Pain Symptom Manage 2014; 48(6): 1108-1116.

33. National Palliative End of Life Care Partnership. Ambitions for palliative and end of life care: a national framework for local action 2015-2020, 2015, www.endoflifecareambitions.org.uk (accessed 6 December 2017).

34. Davidson I, Whyte F and Richardson R. Self-management in palliative medicine. Curr Opin Support Palliat Care 2012; 6(4): 432-437.

35. Johnston B, Rogerson L, Macijauskiene J, et al. An exploration of self-management support in the context of palliative nursing: a modified concept analysis. BMC Nurs 2014; 13: 21.

36. Gunnarsdottir S, Donovan HS and Ward S. Interventions to overcome clinician- and patient-related barriers to pain management. Nurs Clin North Am. 2003; 38: 419434, v.

37. Mehta A and Chan LS. Understanding of the concept of 'total pain'. J Hosp Palliat Nurs 2008; 10(1): 26-32.

38. McCaffery M and Ferrell BR. Nurse's knowledge about cancer pain: a survey of five countries. J Pain Symptom Manage 1995; 10(5): 356-369.

\section{Appendix 1}

\section{HCP focus group schedule}

\section{Knowledge}

1. Are you familiar with any constipation guidelines in the unit?

2. What is your understanding of constipation within palliative care patients?

\section{Management}

3. Can you take me briefly through the various steps in how patients with constipation are assessed, managed and treated for constipation in an SPC unit?

4. Which HCPs are involved in the assessment, management and treatment of patients with constipation and briefly, what does each of them do?

5. Do you think assessing, managing and treating constipation is part of your role (prompt: nursing, medic and pharmacist, do they see it as being appropriate)?

6. Do you seek opinions of colleagues/others in assessing, managing and treating someone with constipation? (If so, who and why?)

7. Is there any training/education needed to help facilitate these processes around assessment, management and treatment?

\section{Barriers and facilitators}

8. Have you ever experienced any barriers in assessing, managing and in treating for constipation? (Prompt: nursing, medic and pharmacist, what are their beliefs and capabilities, motivations, environmental context and resources)

9. Have you ever experienced any facilitators in assessing, managing and in treating for constipation? (Prompt: nursing, medic and pharmacist, what are their beliefs and capabilities, motivations, environmental context and resources)

\section{Intervention/education}

10. In terms of content, what do you think are the essential parts of the educational intervention for assessing, managing and treating constipation?

11. What do you think about different methods of intervention delivery? (Prompt: face to face, potential use of technology, interaction with peers and clinical scenarios)

12. Who should deliver the intervention?

13. Do you think there is anything within the hospice setting that would support or hinder the implementation of an intervention (Prompt: culture, resources and wider setting beyond the hospice).

\section{Patient/carer interview schedule}

\section{Questions}

1. What does constipation mean to you?

2. How do you think constipation affects you (the person you care for)? (Prompt, physically, emotionally and socially)

3. What bothers you (and the person you care for) most about constipation? (Prompt, physically, emotionally and socially)

4. What has been your journey/experience of constipation over time?

5. Who helps manage your/the patient's constipation? (Prompt: how)

6. How do you feel about the number of laxatives the person you care for takes? (Prompt: taking too many, complying to guidelines and relying on personal judgement for usage)

7. What training (if any) do you think HCPs require in accessing, treating and managing constipation? 